\title{
Status of hepatitis B virus in the aetiology of uveitis in Great Britain
}

\author{
P. I. MURRAY, J. PRASAD, AND A. H. S. RAHI \\ From the Institute of Ophthalmology, University of London, and Moorfields Eye Hospital, London
}

SUMMARY Viruses have been demonstrated or suspected as the causative agents of various types of uveitis. Hepatitis B virus (HBV), apart from causing hepatitis, has also been implicated in the pathogenesis of systemic vasculitis, for example in glomerulonephritis and polyarteritis nodosa. It is therefore possible to postulate that a similar vasculitic process might occur in the eye leading to intraocular inflammation. A recent report from Switzerland suggests that HBV may be implicated in the aetiology of uveitis, as hepatitis B surface antigen $(\mathrm{HBsAg})$ was found in the serum of $13 \%$ of cases of uveitis. Since the status of HBV in the aetiology of uveitis in Great Britain has not been investigated, we have examined serum from 200 cases of uveitis of various clinical types for the presence of circulating HBsAg. Only 4 cases $(2 \%)$ were found to be $\mathrm{HBsAg}$ positive. This study failed, therefore, to confirm $\mathrm{HBV}$ as an important cause of uveitis in this country, but one cannot exclude the possibility that it may play a pathogenetic role in a small proportion of such cases.

\begin{abstract}
Although the aetiology of endogenous uveitis is largely unknown, for many years various viruses have been implicated in its pathogenesis. ${ }^{1}$ Recently not only have viruses been isolated from the eye ${ }^{2-4}$ but electron microscopy has revealed virus particles in uveal tissue. ${ }^{5}$ Hepatitis B virus (HBV) is generally associated with acute hepatitis, which in some cases becomes chronic and may lead to postnecrotic cirrhosis and possibly hepatocellular carcinoma. But some persons after infection with HBV remain asymptomatic, with little or no liver damage. This is associated with transient appearance in the blood of virus-derived surface antigen ( $\mathrm{HBs} \mathrm{Ag}$ ), previously known as Australia antigen, leading to the development of protective antibodies. The antigen may persist in certain individuals for prolonged periods with minimal immune response, leading to a chronic carrier state.
\end{abstract}

Recently it has become recognised that HBV may be responsible for a variety of ill understood systemic diseases with vasculitis as a common denominator. Persistent production of surface antigen ( $\mathrm{HBsAg}$ ) and antigen derived from the virus core $(\mathrm{HBcAg})$ and consequent development of specific antibodies lead to the formation of circulating immune complexes

Correspondence to Dr P. I. Murray, Department of Pathology, Institute of Ophthalmology, 17-25 Cayton Street, London EC1V 9AT. that activate inflammatory components of complement producing tissue damage primarily in the vascular system. ${ }^{6}$ It is not surprising therefore that HBV has been implicated in the development of certain forms of glomerulonephritis, ${ }^{78}$ polyarteritis nodosa, ${ }^{10}$ polymyalgia rheumatica, ${ }^{11}$ infantile papular acrodermatitis, ${ }^{12}$ essential mixed cryoglobulinaemia ${ }^{13}$ and arthralgia. ${ }^{14}$ It is logical therefore to suspect that HBV-associated immune complexes may initiate intraocular inflammation, particularly uveitis.

A study from Switzerland ${ }^{15}$ indicates that a statistically significant proportion of patients $(13 \%)$ with uveitis contain virus-derived surface antigen (HBsAg) in their blood. The present investigation, therefore, is an attempt to evaluate the status of hepatitis B virus in the aetiology of uveitis in Great Britain.

\section{Materials and methods}

Blood from 200 patients attending Moorfields Eye Hospital with various clinical types of uveitis was collected by venepuncture and allowed to clot naturally. After centrifugation the serum obtained was screened for HBsAg by means of Hepatitis B Antigen HA Screening Kit (Wellcome). This method of direct passive agglutination provides a particularly 
Table 1 Results in patients divided into 10 clinical groups

\begin{tabular}{|c|c|c|c|c|c|}
\hline \multirow[t]{2}{*}{ Diagnosis } & \multirow[t]{2}{*}{ Number } & \multicolumn{2}{|c|}{ Sex } & \multirow[t]{2}{*}{$H B s A g+v e$} & \multirow[t]{2}{*}{$\%+v e$} \\
\hline & & $F$ & $M$ & & \\
\hline Acute anterior uveitis & 128 & 58 & 70 & 4 & 3 \\
\hline Chronic anterior uveitis & 14 & 8 & 6 & - & - \\
\hline Chronic posterior uveitis & 18 & 10 & 8 & - & - \\
\hline Chronic generalised uveitis (panuveitis) & 18 & 10 & 8 & - & - \\
\hline Pars planitis (intermediate uveitis) & 10 & 3 & 7 & - & - \\
\hline Behçet's disease & 3 & 2 & 1 & - & - \\
\hline Juvenile chronic arthritis (Still's disease) & 1 & - & 1 & - & - \\
\hline Vogt-Koyanagi-Harada syndrome & 1 & 1 & - & - & - \\
\hline Lens-induced uveitis & 2 & 1 & 1 & - & - \\
\hline Retinal vasculitis with posterior uveitis & 5 & 2 & 3 & - & - \\
\hline Total & 200 & 95 & 105 & $\begin{array}{l}4 \text { (2 Male) } \\
\text { (2 Female) }\end{array}$ & 2 \\
\hline
\end{tabular}

rapid and simple test system with high sensitivity. Proper controls were set up to exclude false positive results due to natural antibodies in patients' serum to the indicator cell system. All positive sera were further checked by confirmatory tests according to the procedure recommended by the suppliers, and at least a 4-fold greater titre in the test row was required to regard it positive.

\section{Results}

Two hundred patients with uveitis whose ages varied from 11 to 74 years were divided into 10 different clinical groups. As shown in Table 1, only 4 of the 200 blood samples tested were positive for $\mathrm{HB}$ surface antigen (HBsAg) in titre $>1: 8$; all had acute anterior uveitis.

\section{Discussion}

Viruses implicated in the aetiology of uveitis include herpes simplex, varicella-zoster, cytomegalovirus, adenovirus, and various myxo- and arboviruses. Hepatitis B virus is a recent addition to this growing list. The uveal involvement in a virus infection may be endogenous via the blood stream or, in the case of herpes simplex, via sensory nerves, or it may be exogenous through damaged cornea. The latter possibility gains support as systemic infection via the ocular route has been reported in 2 papers. Firstly, blood from a patient ( $\mathrm{HBsAg}+\mathrm{ve}$ ) undergoing renal dialysis was accidently splashed into the eye of a nurse who subsequently developed serum hepatitis, ${ }^{16}$ and secondly plasma from a patient with $\mathrm{HBV}$ was placed on the cornea of a chimpanzee-the animal becoming infected 9 weeks later. ${ }^{17}$

Three distinct antigenic components are associated with hepatitis $B$ virus ${ }^{18-21}$ : the HB surface antigen ( $\mathrm{HBsAg}$ ), the antigen associated with the virus core $(\mathrm{HBcAg})$, and the e antigen ( $\mathrm{HBeAg})$ associated with infectivity and transmissibility. A further component of the virus is a DNA polymerase in the core, and there is the DNA itself, which is a closed coil of double stranded DNA of molecular weight $1.6 \times 10^{6}$. Ultrastructurally 3 morphological forms have been recognised. The $\mathrm{HBcAg}$ and the polymerase are present only in the core $(27 \mathrm{~nm})$ of the double shelled particle $(45 \mathrm{~nm})$ known as the Dane ${ }^{22}$ particle. The third type of particle $(22 \mathrm{~nm})$ contains no DNA and appears to consist of excess coat material. The HBsAg is on the surface of the latter 2 types of particles. The Dane particle contains the DNA and is presumed to be the infective virus. The $\mathrm{HBeAg}$ is located on the Dane particle, probably on the surface, but is also free in the serum. For all practical purposes the detection of $\mathrm{HBsAg}$ in a patient's blood is tantamount to declaring this blood infective - that is, that it contains HBV.

Infection with HBV is a result of transfer of virus from an infected to a susceptible individual. The infection may be transmitted by accidental inoculation of minute amounts of blood or fluid contaminated with blood such as may occur during medical, surgical, and dental procedures, immunisation with inadequately sterilised syringes and needles, intravenous and percutaneous drug abuse, tattooing, ear and nose piercing, acupuncture, laboratory accidents, and accidental inoculation with razors and similar sharp objects that have been contaminated with blood. There is much evidence of the transmission of hepatitis B by intimate contact and by the sexual route. The sexually promiscuous, particularly male homosexuals, are at very high risk. Since HBsAg is found not only in blood but also in various body fluids such as saliva, genital secretions, and breast milk it is not surprising that these have been implicated as vehicles of transmission of infection. Recently it has been demonstrated in tears from about half of seropositive individuals,,$^{23}$ which raises 
the possibility of cross-infection through conjunctival-corneal route via tonometers ${ }^{24}$ and contact lenses..$^{25} \mathrm{It}$ is also possible that the virus finds its way into other ocular fluids such as aqueous humour, thus challenging the uvea directly.

The presence of $\mathrm{HBsAg}$ in blood and body secretions in apparently healthy individuals is related to a carrier state, which may be defined as the persistence of the antigen in the circulation for longer than 6 months.

In Northern Europe including Great Britain, North America and Australia chronic carriers number $0.2 \%$ or less of the general population although a much higher frequency may be found in selected groups such as doctors, dentists and nurses. A higher frequency (i.e. 5\%) is observed in Central and Eastern Europe while in some parts of Africa, Asia, ${ }^{26}$ Pacific region as many as $10-20 \%$ or more of the apparently healthy population may be carriers. ${ }^{27}$

In the present study we found that $2 \%$ (i.e. 4 out of the 200 patients tested) had circulating HBsAg. This is 10 times higher than one would expect from the indigenous control population but could be regarded normal for several other countries. All 4 patients had acute anterior uveitis, with equal sex distribution. Since we did not perform a longitudinal study, it is not known if these patients represent a chronic carrier state or if blood was collected during the prodromal phase of acute hepatitis. The Swiss study ${ }^{15}$ reported that $13 \%$ of patients with uveitis were $\mathrm{HBsAg}$ positive, this is a much higher figure than obtained in the present investigation. The discrepancy could be either due to geographical differences or to different methods used to detect HBsAg. They used solidphase radioimmunoassay (Abbott), whereas direct passive haemagglutination was used in our study. It is well accepted, however, that the technique we used is highly sensitive and is superior to immunodiffusion in agar, counterimmunoelectrophoresis, and complement fixation; it is only marginally less sensitive than radioimmunoassay.

In conclusion HBV appears to play an important role in the pathogenesis of vasculitis in various systemic diseases, ${ }^{6}$ and it is conceivable that it may contribute in a few instances to the aetiology of uveitis through an immune complex mediated reaction. We do not feel, however, that HBV plays an important part in the pathogenesis of uveitis in this country.

We are thankful to Miss K. Betts for her secretarial help. P.I.M. is at present the recipient of the Friends of Moorfields research fellowship grant.

\section{References}

1 Duke-Elder S, Perkins ES. Diseases of the uveal tract. In: Duke-
Elder S, ed. System of ophthalmology. London: Kimpton, 1966; 9: 332-58.

2 Cotlier E, Fox J, Smith M. Rubella virus in the cataractous lens of congenital rubella syndrome. Am J Ophthalmol 1966; 62: 233-5.

3 Cibis A, Burde RM. Herpes simplex virus-induced congenital cataracts. Arch Ophthalmol 1971; 85: 220-3.

4 Consoli G, Castro A. Contributions to the study of herpetic uveitis. Ann Ottal 1977; 103: 1-8.

5 Martenet A-C. Role of viruses in uveitis. Trans Ophthalmol Soc UK 1981; 101: 308-11.

6 London WT. Hepatitis B virus and antigen-antibody complex diseases. N Engl J Med 1977; 296: 1528-9.

7 Brzosko WJ, Krawczynski K, Nazarewicz T, Morzycka M, Nowoslawski A. Glomerulonephritis associated with hepatitis B surface antigen immune complexes in children. Lancet 1974; ii: 477-82.

8 Combes B, Stastny P, Shorey J, et al. Glomerulonephritis with deposition of Australia antigen-antibody complexes in glomerular basement membrane. Lancet 1971; ii: 234-7.

9 Gocke DJ, Hsu K, Morgan C, Bombardieri S, Lockshin M, Christian CL. Association between polyarteritis and Australia antigen. Lancet 1970; ii: 1149-53.

10 Fye KH, Becker MJ, Theofilopoulos AN, Moutsopoulos H, Feldman J-L, Talal N. Immune complexes in hepatitis B antigen associated periarteritis nodosa. Am J Med 1977; 62: 783-91.

11 Bacon PA, Doherty SM, Zuckerman AJ. Hepatitis-B antibody in polymyalgia rheumatica. Lancet 1975 ; ii: $476-8$.

12 Gianotti F. Papular acrodermatitis of childhood: an Australia antigen disease. Arch Dis Child 1973; 48: 794-9.

13 Mclntosh RM, Koss MN, Gocke DJ. The nature and incidence of cryoproteins in hepatitis $\mathrm{B}$ antigen $(\mathrm{Hbs} \mathrm{Ag}$ ) positive patients. $Q J$ Med 1976; 45: 23-8.

14 Wands JR, Mann E, Alpert E, Isselbacher KJ. The pathogenesis of arthritis associated with acute hepatitis-B surface antigenpositive hepatitis. J Clin Invest 1975; 55: 930-6.

15 Grob PJ, Martenet A-C, Witmer R. Nonspecific immune parameters and hepatitis $\mathrm{B}$ antigens in patients with uveitis. Mod Probl Ophthalmol 1976; 16: 254-8.

$16 \mathrm{Kew}$ MC. Possible transmission of serum (Australia antigen $+v e$ ) hepatitis via the conjunctiva. Infect Immun 1973; 7: 823-4.

17 Bond WW, Petersen NJ, Favero MS, Ebert JW, Maynard JE. Transmission of type B viral hepatitis via eye inoculation of a chimpanzee. J Clin Microbiol 1982; 15: 533-4.

18 Blumberg BS, Alter AJ, Visnich S. A new antigen in leukaemic sera. JAMA 1965; 191: 541-6.

19 Almeida JD, Rubenstein D, Scott EJ. New antigen-antibody system in Australia antigen +ve hepatitis. Lancet 1971; ii: 1225-7.

20 Magnius LO, Espmark JA. New specificities in Australia antigen + ve sera distinct from the le Bouvier determinants. J Immunol 1972; 109: 1017-21.

21 Hoofnagle JH, Gerety RJ, Barker LF. Antibody to hepatitis-B virus core in man. Lancet 1973; ii: 869-73.

22 Dane DS, Cameron CH, Briggs M. Virus-like particles in serum of patients with Australia antigen associated hepatitis. Lancet $1970 ;$ i: $695-8$.

23 Darrell RW, Jacob GB. Hepatitis B surface antigen in human tears. Arch Ophthalmol 1978; 96: 674-6.

24 Moniz, E, Feldman F, Newkirk M, Feinman SV, Berris B. Removal of hepatitis B surface antigen from a contaminated applanation tonometer. Am J Ophthalmol 1981; 91: 522-5.

25 Maass G, Claas W, Schliermann T, Conrads H. Risk of transmission of hepatitis B by contact lenses. Ophthalmologica 1979; 178: 148-55.

26 Mital VN, Gupta OP, Nigam DK, Saxena PC, Kumar S. Pattern of hepatitis B antigen-contact and carrier state in Northern India. J Indian Med Assoc 1980; 74: 105-6.

27 Zuckerman AJ. Acute viral hepatitis. J R Coll Physicians Lond $1981 ; 15: 88-94$ 